\title{
Short-term and Long-term Outcome Predictions of Older Adults Based on Geriatric Scores: A Prospective Study
}

\author{
(D) Preeti Chhabria1', (1) Ketan Vijay Kargirwar², (1) Nirankar Bhutaka2, (D) Divya Gopal'1, (1) Mayur H Patel2 \\ 1 Department of Internal Medicine, Sir H.N. Reliance Foundation Hospital and Research Centre, Mumbai, India \\ ${ }^{2}$ Critical Care Medicine Sir H.N. Reliance Foundation Hospital and Research Centre, Mumbai, India
}

\begin{abstract}
Objective: With the increasing proportion of older patients ( $\geq 80$ years) requiring medical care, it becomes highly essential to determine their health outcomes, which will further aid in providing personalized medical care. However, there are limited studies suggesting the use of geriatric scores, namely, frailty score, comorbidity-polypharmacy score (CPS), and Katz index for outcome prediction in the Indian population. Thus, the objective of the current study was to assess the reliability of each of the aforementioned three parameters in predicting the health outcomes (survival) of older patients.
\end{abstract}

Materials and Methods: The study population consisted of 300 patients, aged 80 years and above, admitted to the intensive care unit ( $\mathrm{n}=150$ ) and wards $(n=150)$ during the study period of 18 months. We recorded patient demographics and sequential organ failure assessment scores at 24 hours of hospitalization, categorized patients based on clinical frailty scale (CFS), activities of daily life index and CPS at admission and examined their survival at 30 and 180 days.

Results: The prevalence of the older population among the overall patient population in the hospital was estimated to be $8.85 \%$. Through our analyses, we found that both 30-day and 180-day survival rates were decreased with lower Katz scores $\leq 4$ and higher CFS $>3$ and CPS $>7$ scores, suggesting the use of the three scores as independent predictors of short-term and long-term outcomes in the older population.

Conclusion: We suggest the potential use of the geriatric scores (CFS, CPS, and Katz index) for outcome prediction in the Indian population.

Keywords: Activities of daily life, comorbidity-polypharmacy, older patients, frailty, outcome prediction, survival

\section{Introduction}

The outcome prediction plays a pivotal role in determining the health conditions of patients, particularly in intensive care medicine wherein increasing attention has been on developing severity models for the outcome prediction (1). In recent years, outcome prediction in the older population ( $\geq 80$ years) has gained substantial attention because of the increased life expectancy in several countries (1). Thus, predicting the short-term and long-term outcomes in the aforementioned group would help in better prognostication and in providing personalized medical care to this biologically heterogeneous population.
Previous research has demonstrated that associating age with the severity of illness at admission could only partially explain the survival of older patients, suggesting the inefficiency of traditional prognostic scoring systems (2). Furthermore, it has been suggested that, in older patients ( $\geq 80$ years), the ability to deal with severe stressors such as critical illness correlates with the geriatric syndromes, including frailty (3), cognitive decline, and deteriorating performance on the activity of daily life (ADL) scale along with comorbidity (2). Frailty is a clinical state of older patients characterized by age-associated failures of multiorgan systems, thereby rendering the patients with increased vulnerability for adverse health outcomes (4). Additionally, several studies have suggested the importance

Address for Correspondence: Ketan Vijay Kargirwar, Critical Care Medicine Sir H.N. Reliance Foundation Hospital and Research Centre, Mumbai, India Phone: +91 8454888103 E-mail: ketankargirwar00@gmail.com ORCID: orcid.org/0000-00017091-1844

Received: 04.09.2021 Accepted: 08.01.2022

Cite this article as: Chhabria P, Kargirwar KV, Bhutaka N, Gopal D, Patel MH. Short-term and Long-term Outcome Predictions of Older Adults Based on Geriatric Scores: A Prospective Study. Eur J Geriatr Gerontol 2022;4(2):71-78

${ }^{\circ}$ Copyright 2022 by the Academic Geriatrics Society / European Journal of Geriatrics and Gerontology published by Galenos Publishing House. 
of frailty score in geriatric medicine as frailty is associated with increased risk of poor outcomes such as falls, depression, disability, and mortality (5). A study by Hao et al. (6) reported the prevalence of frailty among older adults and showed an increase in death and hospital readmission rates of frail patients when compared with those of non-frail patients. Moreover, the care of old frail patients is often complicated by conditions such as comorbidity and polypharmacy; however, the correlation between frailty and comorbidity-polypharmacy remains to be investigated. Multiple chronic health conditions usually develop along with the increasing age, and modern medical management of chronic medical conditions often put the patients at a risk of polypharmacy or multiple medications. Evans et al. (7) introduced the comorbidity-polypharmacy score (CPS), a sum of the number of pre-injury medications and the number of comorbidities, to better quantify the severity of comorbidities and complement existing injury severity scoring tools for precise prediction of clinical outcomes in the older population. Amemiya et al. (8) stated that more than $10 \%$ of patients older than 80 years may have extended postoperative disability. Additionally, postoperative performance of patients, assessed by ADL and quality of life, have become essential to accurately predict outcomes of surgical treatment for the older population (8). Frequently, the ADL is determined using the Katz index of independence as it assesses the basic activities of daily living. Necessity of supervision, personal assistance, directive assistance, or total care for any dependent function of the Katz index are used as parameters to examine the functional ability of older people (9).

Thus, the aforementioned factors will help in more accurately predicting the functional recovery of older patients from major illness after hospitalization. However, there is limited evidence suggesting the use of frailty score, CPS, and Katz index of independence in ADL for predicting the short term and longterm outcomes of older population. Therefore, in this study, we aimed to assess the reliability of each of the three factors, namely, frailty score, comorbidity-polypharmacy score, and ADL index in predicting the health outcomes (survival) of older patients. Upon admission of the patient to the hospital, each of the three scores were correlated with survival at 30 and 180 days to establish trends in the short-term and long-term survival of patients, thereby suggesting the potential use of the three scores for outcome prediction in the Indian population.

\section{Materials and Methods}

\section{Patients and methods}

The study population consisted of 300 patients, aged 80 years and above, admitted to the intensive care unit (ICU) $(n=150)$ and wards $(n=150)$ during the study period of 18 months from November 21, 2019, to May 21, 2021. The study was conducted at the Department of Critical Care Medicine and Clinical Medical Wards, Sir H. N. Reliance Foundation Hospital \&t Research Centre $(\mathrm{RFH})$, Mumbai, India and approved by the Institutional Ethics Committee of the hospital (IEC number: HNH/IEC/2019/OCS/ IMED/11). All patients, aged 80 years and above, admitted for more than 24 hours in ICU and wards were considered for the study. Consistently, patients who were discharged, left against medical advice, or died within 24 hours of hospitalization were excluded from the current study. Additionally, patients or substitute decision makers who refused to provide study-related information were excluded from the study. The sample size was decided based on the study outcomes reported by Siriwardhana et al. (10). The study suggested that the prevalence of frailty is $26 \%$ in the age group 80 years and above in low-income and middle-income countries. Therefore, the study population consisted of 300 patients based on the fact that if $26 \%$ of the subjects in the population have the factor of interest, the study would require a sample size of 296 for estimating the expected proportion with $5 \%$ absolute precision.

This present study is a prospective, observational, analytical study without any control group. No additional intervention such as drugs, diagnostic procedures, or surgery were performed on the patients, except those as per usual hospital treatment protocols and methods. Informed consent was obtained from patients included in this study. Data were collected and analyzed from the electronic medical record of RFH for all adult patients admitted to the ICU and wards, as per the inclusion criteria. The following 19 parameters were recorded after 24 hours of hospitalization: Demographic profile of the patient such as age, sex, and comorbidity; date of ICU/ward admission; reason for ICU/ward admission; habitat before hospital admission; sequential organ failure assessment (SOFA) score at 24 hours; clinical frailty scale [minor (CFS $\leq 3$ ), moderate (CFS 4-6), and severe (CFS 7-9)] at admission (11); ADL index (Katz ADL) [no impairment (Katz index $=6$ ), moderate impairment (Katz index $\leq 4)$, and severe impairment (Katz index $\leq 2)]$ at admission (9); CPS [minor (CPS $\leq 7$ ), moderate (CPS 8-14), and severe (CPS $>15)$ ] at admission (12); intubation and ventilation; noninvasive ventilation; tracheostomy; vasoactive inotropes drugs; renal replacement therapy; length of stay in ICU; length of stay in hospital; withholding/withdrawal of life sustaining care; and survival at 30 and 180 days. We used CFS to describe patients' frailty prior to hospital admission with 9 possible classes varying from very fit prior to the acute illness to terminally ill. Similarly, we used Katz index to assess the patients' ability to perform activities of daily life independently and was stratified into 6 classes ranging from patient independent to very dependent, whereas CPS was used to determine the number of pre-injury medications and comorbidities associated with the patients. Based on CPS, patients were classified into 3 categories, namely, 
mild (CPS 0-7), moderate (8-14), and severe (CPS >15). The scoring of these geriatric tests was performed by physicians.

\section{Statistics}

We estimated the mean and standard deviation or median and interquartile range for continuous variables. We estimated the proportions for categorical variables. The mean values were compared using the t-test (for independent groups), and the non-normal data were compared using the Mann-Whitney $\mathrm{U}$ test. The proportions across groups were compared using the chi-square test or the Fisher's Exact test for low expected cell counts. We used the logistic regression models for multivariate analysis. The outcome in the variable was survival (short term: 30 days or long term: 180 days). The primary explanatory variable was score category (Katz index, frailty score, and CPS). The additional variables in the models were: Type of patient (ward or ICU), age, and gender. We built separate models for each score and $p$-values of $<0.05$ were considered statistically significant. Data were analyzed using the stata version 15.1 software (OStataCorp, College Station, Texas, USA).

\section{Results}

\section{Patient characteristics of older patients ( $\geq \mathbf{8 0}$ years) in a tertiary care hospital}

In total, 300 patients were included in this study, which consisted of 150 patients each admitted to the ward and ICU. The prevalence of older population ( $\geq 80$ years) among the overall patient population in the hospital was found to be 8.85\% [95\% confidence interval (Cl): 8.27\% to 9.46\%]. Of the overall patient population, we found that the distribution of older male and female population ( $\geq 80$ years) was $9.00 \%$ (95\% Cl: $8.21 \%$ to $9.85 \%$ ) and $8.69 \%$ (95\% Cl: $7.87 \%$ to $9.57 \%)$. In our study group, the number of males admitted to the hospital were higher than that of females (58.7\% vs $41.3 \%$ in ward and $52.0 \%$ vs $48.0 \%$ in ICU) (Table 1). Moreover, the average age ( \pm standard deviation) of patients admitted to the ward and ICU was estimated to be $83.7 \pm 3.4$ years and $84.9 \pm 4.3$ years, respectively. Majority of the patients admitted to the hospital ward did not receive both invasive (intubation and tracheostomy) and non-invasive ventilation, vasoactive medication, and renal replacement therapy. Median length of stay in the ICU was 4.5 days. Furthermore, no considerable differences in the median SOFA scores between patients admitted to the ward and ICU were found. We also determined the reasons for hospital admission of patients and found that the most common cause of admission among ward patients was cardiovascular diseases (25.3\%), whereas that among ICU patients was neurological diseases $(2.3 \%)(p<0.001)$. Most of the information regarding ICU patients was collected from family and physicians, whereas almost all of the information regarding ward patients were collected from patients, family, and doctors. Survival records for all patients were obtained through telephonic conversations and family physicians.

\section{Association of CFS, CPS, and ADL index with survival at 30 days}

Geriatric scores, namely, CFS, CPS, and Katz ADL index were estimated for all the patients included in our study group, and these scores were correlated with survival at both 30 and 180 days. The 30-day survival among ICU patients was estimated to be $83 \%$, whereas $98 \%$ patients admitted to the ward survived after 30 days of admission (Figure 1). The number of impaired patients with a high degree of comorbidity was higher in the ICU than in the ward. Overall, $60.67 \%$ patients admitted to the ICU were impaired (Katz index $\leq 4$ ) and 4\% patients had a high degree of comorbidity (CPS >15), whereas 48.67\% patients admitted to the ward were impaired (Katz index $\leq 4$ ) and only $1.33 \%$ patients had a high degree of comorbidity (CPS $>15$ ), as expected. Interestingly, the number of frail patients to the ICU (12\%) were lower than those admitted to the ward (20\%) (Figure 2). Among ward patients, the 30-day survival of patients with moderate impairment was estimated to be $98 \%$, whereas that of patients with severe impairment was estimated to be $82 \%$ $(p<0.001)$. Similarly, significant differences between the 30day survival of patients with CPS $>7$ (97\%) and CPS >15 (50\%) $(p<0.001)$ were observed. However, no statistically significant differences were observed between the short-term survival of non-frail and frail patients in both the ward [99\% (CFS $\leq 3$ ), 93\% (CFS 4-6), and 100\% (CFS 7-9), $p=0.10$ ] and ICU patients [83\% (CFS $\leq 3$ ), 78\% (CFS 4-6) $p=0.56$ ] (Table 2). On further analysis, we found that lower Katz scores (Katz index $\leq 4$ ) and higher frailty (CFS $>3$ ) and comorbidity-polypharmacy scores (CPS $>7$ ) suggested decreased 30-day survival of older patients admitted to both the ICU and the ward (Table 3).

\section{Association of CFS, CPS, and ADL index with survival at 180 days}

Similarly, 180-day survival of patients admitted to the ward and the ICU was determined, and we found that $89 \%$ patients survived after 180 days of ward admission, whereas 75\% patients admitted to the ICU survived (Figure 1). Among ward patients, significant differences between the long-term survival of patients with moderate $(82 \%)$ and severe impairment $(45 \%)$ in comparison to no impairment $(100 \%)$ were observed $(p<0.001)$ (Figure 2). Similarly, significant differences were observed between the 180-day survival of frail [54\% (CFS 4-6) and 50\% (CFS 7-9)] and non-frail patients $(98 \%)(p<0.001)$ and those between CPS $\leq 7$ (98\%) and CPS $>7$ [79\% (CPS 8-14) and 50\% (CPS >15)] $(\mathrm{p}<0.001)$ admitted to the ward (Table 2). Thus, patients with lower Katz scores (Katz index $\leq 4$ ) and higher frailty (CFS 3) and comorbidity-polypharmacy scores (CPS $>7$ ) were less likely to survive. We found significant differences in 180-day survival between the patients with Katz scores of 6 


\begin{tabular}{|c|c|c|c|}
\hline Variables & Ward & ICU & $\mathbf{p}$ \\
\hline & n (\%) & & \\
\hline & $150(100)$ & $150(100)$ & \\
\hline \multicolumn{4}{|l|}{ Demographics } \\
\hline \multicolumn{4}{|l|}{ Age } \\
\hline Mean (SD) & $83.7(3.4)$ & $84.9(4.3)$ & 0.005 \\
\hline \multicolumn{4}{|l|}{ Gender n (\%) } \\
\hline Female & $62(41.3)$ & $72(48.0)$ & 0.296 \\
\hline Male & $88(58.7)$ & $78(52.0)$ & \\
\hline \multicolumn{4}{|l|}{ Reasons for admission } \\
\hline Acute gastrointestinal diseases & $11(7.3)$ & $15(10.0)$ & \multirow{13}{*}{$<0.001$} \\
\hline Acute kidney injury & $1(0.7)$ & $4(2.7)$ & \\
\hline Cardiovascular diseases & $38(25.3)$ & $20(13.3)$ & \\
\hline Chronic liver disease & $2(1.3)$ & $1(0.7)$ & \\
\hline Chronic kidney diseases & $2(1.3)$ & $1(0.7)$ & \\
\hline Elective surgery & $3(2.0)$ & $7(4.7)$ & \\
\hline Endocrine disorders & $1(0.7)$ & $1(0.7)$ & \\
\hline Malignancy & $5(3.3)$ & $5(3.3)$ & \\
\hline Haematological diseases & $0(0)$ & $14(9.3)$ & \\
\hline Neurological disease & $25(16.7)$ & $32(21.3)$ & \\
\hline Respiratory diseases & $31(20.7)$ & $8(5.3)$ & \\
\hline Sepsis & $22(14.7)$ & $24(16.0)$ & \\
\hline Trauma & $9(6.0)$ & $18(12.0)$ & \\
\hline \multicolumn{4}{|l|}{ Clinical Features } \\
\hline SOFA median (IQR) & $1(0,1)$ & $1(0,3)$ & $<0.001$ \\
\hline ICU stay median (IQR) & - & $4.5(3,8)$ & \\
\hline Hospital stay median (IQR) & $4(3,6)$ & $8(5,12)$ & $<0.001$ \\
\hline Invasive ventilation & $0(0)$ & $34(23)$ & $<0.001$ \\
\hline Non-Invasive ventilation & $1(1)$ & $37(25)$ & $<0.001$ \\
\hline Tracheostomy & $0(0)$ & $5(3)$ & 0.06 \\
\hline Vasoactive drug support & $0(0)$ & $36(24)$ & $<0.001$ \\
\hline Renal replacement therapy & $0(0)$ & $9(6)$ & 0.003 \\
\hline Withdrawal of life sustaining care & $1(0.7)$ & $5(3)$ & 0.21 \\
\hline
\end{tabular}

and $\leq 2(p=0.004) ;$ however, no significant differences in the long-term survival of patients with a CPS of 8-14 and $>15$ were observed when compared with those of CPS $<7$. Additionally, we found significant differences in 180-day survival between frail (CFS $>3$ ) and non-frail patients (CFS $\leq 3)(p<0.001)$. Using each of these geriatric scores individually, we found that male patients were less likely to survive than female patients, and ward patients were more likely to survive than ICU patients, as expected, in both long and short terms (Table 3).

\section{Discussion}

According to the population census and United Nations Population Fund estimates there were 104 million older persons (above 60 years of age) in India in 2011 and this number is projected to be 173 million by 2026, thereby leading to an increase in the demands on the health infrastructure (13). Therefore, having efficient prognostic tools are important in making treatment decisions and counselling family members and patients on choices of treatments and outcomes. Thus, we conducted a prospective observational study on 300 patients, which consisted of 150 ICU and ward patients each, to assess the health outcomes of older patients ( $\geq 80$ years) using CFS, CPS, and Katz ADL index. We found that the prevalence of older patients in tertiary care hospital was $8.85 \%$ and no considerable difference between the male and female populations was observed among the study groups. Through our analyses, 


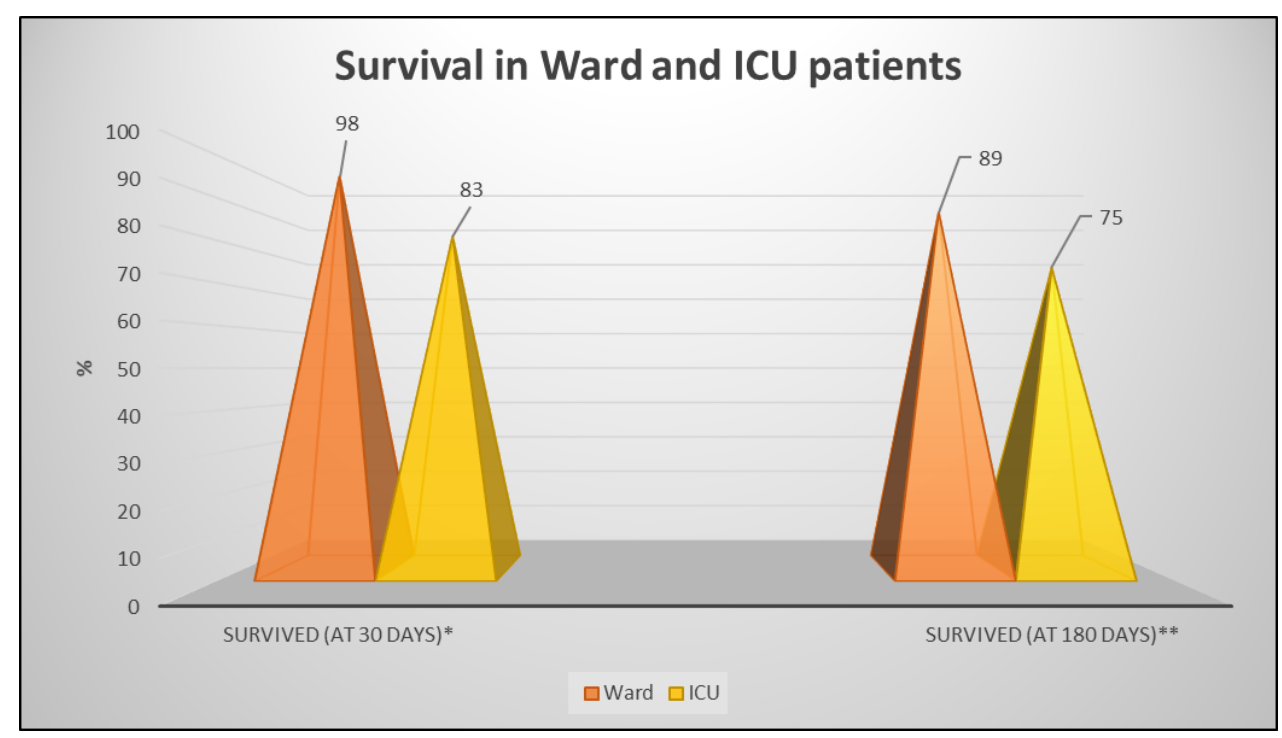

Figure 1. Survival of older ward and intensive care unit (ICU) patients at 30 and 180 days

${ }^{*} p<0.001,{ }^{* *} p=0.003$

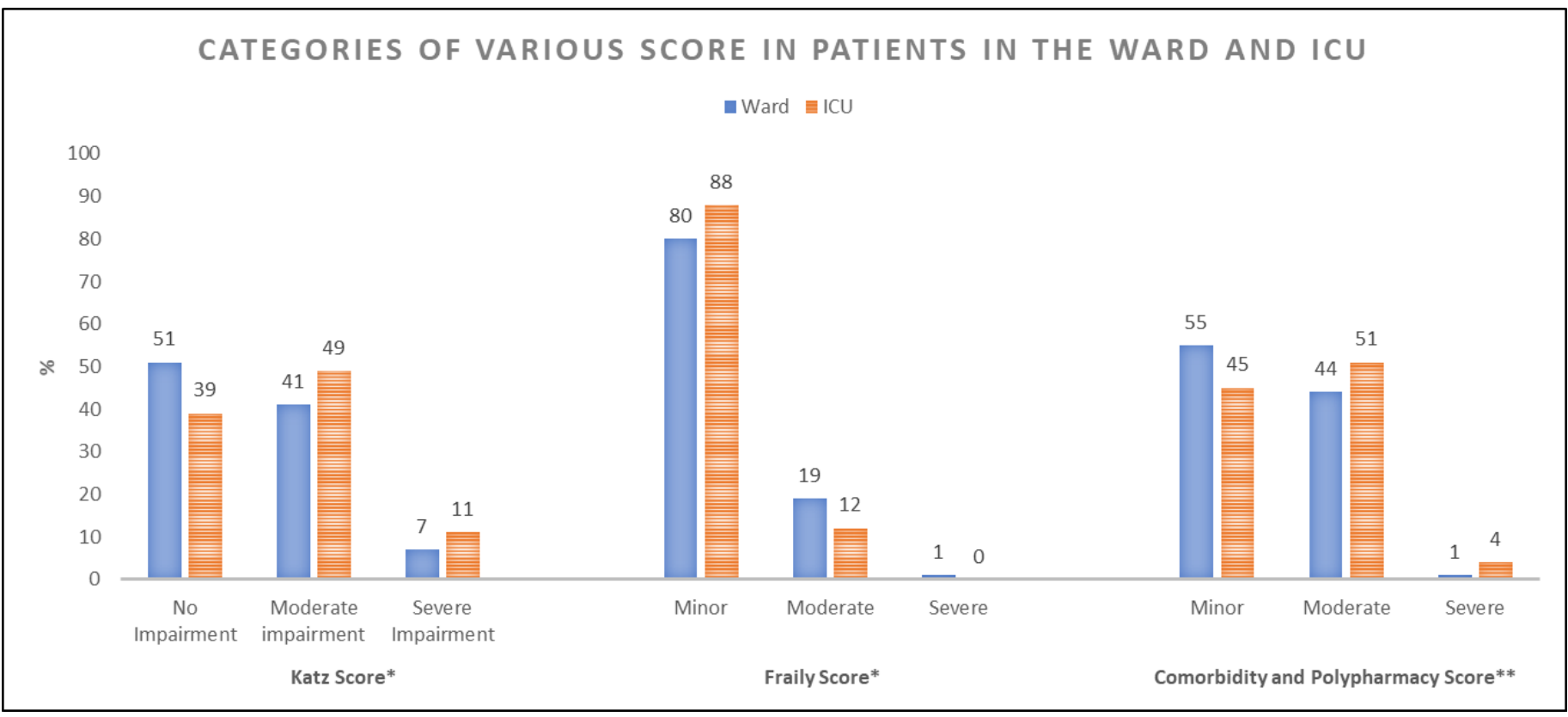

Figure 2. Categorization of older ward and intensive care unit (ICU) patients based on Katz, frailty, and comorbidity-polypharmacy scores

${ }^{*} p<0.09,{ }^{* *} p=0.11$

we found that both 30-day and 180-day survival rates were decreased with lower Katz scores $\leq 4$ and higher CFS $>3$ and CPS $>7$; thus, the three scores can be suggested as independent predictors of short-term and long-term outcomes in the older population.

Frailty is a state of increased vulnerability, characterized by weakness, fatigue, decline in physical activity, and the prevalence of which increases with aging (14). Frailty is an important geriatric syndrome that is dynamic, fluctuates with time, and reflects multisystem dysfunction. In our study, the prevalence of frailty among ward and ICU patients was found to be $20 \%$ and $12 \%$, respectively. As per the findings of Hewitt et al. (15), the prevalence of frailty (CFS 5-8) was $49.4 \%$ among patients aged 74 years and above, and frailty was associated with early death. Moreover, it has been reported that frailty is significantly associated with 30-day mortality compared with those that were fit or non-frail (16). As expected, we found that the short-term survival rate was $78 \%$ for frail ICU patients, whereas that of non-frail patients was $83 \%$, suggesting the use of CFS in determining health outcomes in the older population. Moreover, as per the study by Shamliyan et al. (17), the correlation of frailty with poor survival was significant in both 


\begin{tabular}{|c|c|c|c|c|c|c|c|c|}
\hline & \multicolumn{4}{|c|}{ Short term (30 days) } & \multicolumn{4}{|c|}{ Long term (180 days) } \\
\hline & \multicolumn{2}{|l|}{ Ward } & \multicolumn{2}{|l|}{ ICU } & \multicolumn{2}{|l|}{ Ward } & \multicolumn{2}{|l|}{ ICU } \\
\hline & All & Survived & All & Survived & All & Survived & All & Survived \\
\hline & n (\%) & n (\%) & n (\%) & n (\%) & n (\%) & n (\%) & n (\%) & n (\%) \\
\hline All & $150(100)$ & $147(98)$ & $150(100)$ & $124(83)$ & $150(100)$ & $133(89)$ & $150(100)$ & $113(75)$ \\
\hline \multicolumn{9}{|l|}{ Katz score } \\
\hline No impairment & $77(51)$ & 77 (100) & 59 (39) & $50(85)$ & $77(51)$ & 77 (100) & $59(39)$ & $46(78)$ \\
\hline Moderate impairment & $62(41)$ & $61(98)$ & $74(49)$ & $61(82)$ & $62(41)$ & $51(82)$ & $74(49)$ & $54(73)$ \\
\hline Severe impairment & $11(7)$ & $9(82)$ & $17(11)$ & $4(24)$ & $11(7)$ & $5(45)$ & $17(11)$ & $13(76)$ \\
\hline Moderate & $28(19)$ & $26(93)$ & $18(12)$ & $14(78)$ & $28(19)$ & $15(54)$ & $18(12)$ & $12(67)$ \\
\hline Severe & $2(1)$ & $2(100)$ & $0(0)$ & $0(0)$ & $2(1)$ & $1(50)$ & $0(0)$ & $0(0)$ \\
\hline$p$ & & 0.10 & & 0.56 & & $<0.001$ & & 0.36 \\
\hline \multicolumn{9}{|l|}{ Polypharmacy score } \\
\hline Minor CPS & $82(55)$ & $82(100)$ & $67(45)$ & $55(82)$ & $82(55)$ & $80(98)$ & $67(45)$ & $49(73)$ \\
\hline Moderate CPS & $66(44)$ & $64(97)$ & $77(51)$ & $64(83)$ & $66(44)$ & $52(79)$ & $77(51)$ & $59(77)$ \\
\hline Severe CPS & $2(1)$ & $1(50)$ & $6(4)$ & $5(83)$ & $2(1)$ & $1(50)$ & $6(4)$ & $5(83)$ \\
\hline$p$ & & $<0.001$ & & 0.99 & & $<0.001$ & & 0.80 \\
\hline
\end{tabular}

men and women, however, men were at a greater risk of death than women, which was consistent with our findings wherein men were less likely to survive than women at both 30 and 180 days [odds ratio (OR) 0.74 (95\% Cl 0.33-1.67), $p=0.47 ;$ OR 0.50 (95\% Cl 0.26-0.97), $\mathrm{p}=0.04$, respectively].

Furthermore, CPS is used an assessment for outcome prediction based on the patient's comorbidities and pre-injury medications $(18,19)$. Severity of CPS is usually categorized as minor $(0-7)$, moderate (8-14), and severe (>15) (12). In our study, the number of patients with high CPS $>7$ was higher in ICU patients than in ward patients. Moreover, the survival rates were found to be decreased among patients with high CPS in both ICU and ward patients, thereby suggesting that CPS can be used as a parameter to determine the short-term and long-term outcomes of older hospitalized patients. Moreover, several studies have suggested that high CPS is associated with increased mortality (20) and longer hospital and ICU stay (21) in the older population.

ADL is one of the most important factors used for outcome prediction of frail older patients. Several epidemiological studies have suggested the association of ADL with mortality prediction in older patients. Moreover, Nakazawa et al. (22) reported that patients with low ADL scores had higher mortality rates and another study by Mossakowska et al. (23) reported that a higher ADL score is a good predictor of survival. Similar observations were made in our study group wherein both short-term and long-term survival rates were lower in moderately and severely impaired ICU and ward patients than in those with minor or no disability; thus, suggesting that low Katz scores could be a predictor of patient outcomes.

Therefore, to the best of our knowledge, this is the first study on determining the health outcomes of older Indian population ( $\geq 80$ years) using three parameters, namely, CFS, CPS, and Katz index. The current study highlights the prevalence of older patients in a tertiary care hospital, and the potential use of each of the aforementioned factors in determining the shortterm and long-term outcomes of older patients in the Indian population. Finally, one of the limitations of the current study is that the study was conducted based on the data collected from a single centre and may not reflect the same from other centres. Further studies are, therefore, needed to be carried out in the Indian population using the data collected from different centres across the nation for better prognosis among older hospitalized patients aged 80 years and above. Additionally, further studies are needed to be performed to understand the relation between SOFA score and mortality for our study population. Thus, our model needs to be further modified by taking into consideration the patients' nutritional status and SOFA score and correlating them with mortality. Moreover, in this study, we analyzed the association of each of these scores 
Table 3. Health outcome prediction models using Katz score, frailty score, and comorbidity-polypharmacy score in older ward and ICU patients

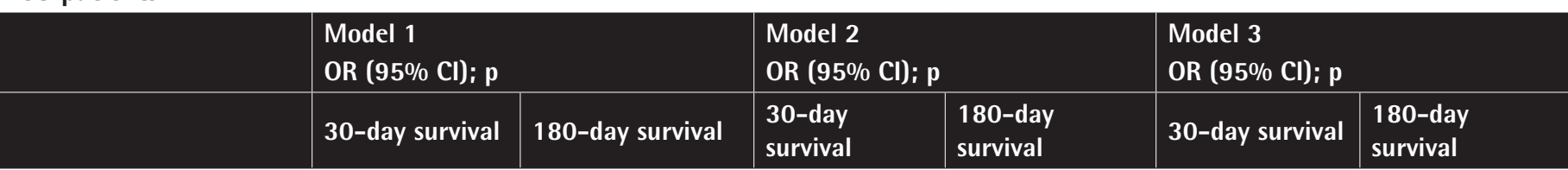

Katz score

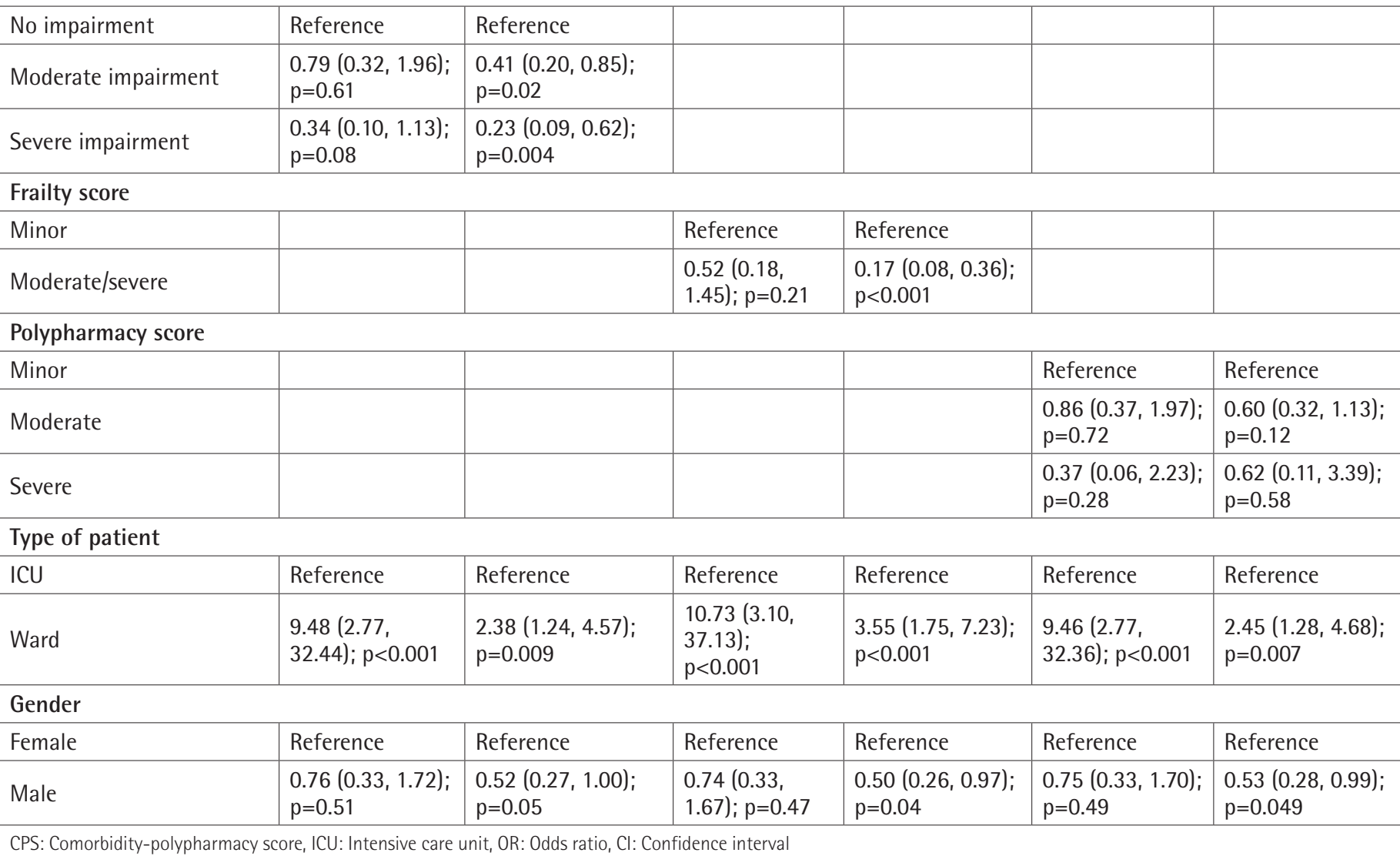

individually; however, further studies need to be carried out to predict health outcomes of older patients based on a model using the interaction of three scores.

\section{Acknowledgement}

We express our gratitude towards Dr. Tarang Gianchandani (CEO) and Dr. Rahul Verma (Academic Director) of Sir H. N. Reliance Foundation Hospital and Research Centre, Mumbai, India for their invaluable contribution in this project. In addition, we extend our gratitude towards Dr. Maninder Setia and Dr. Kavita Shalia for helping us with the data analysis, and Ms. Aradana Mishra for editing the manuscript.

\section{Ethics}

Ethics Committee Approval: Institutional review board approved the study with the IEC number HNH/IEC/2019/OCS/ IMED/11.

Informed Consent: Informed consent was obtained from the participants.
Peer-review: Externally peer-reviewed.

\section{Authorship Contributions}

Surgical and Medical Practices: P.C., K.V.K., N.B., D.G., M.H.P., Concept: P.C., K.V.K., M.H.P., Design: P.C., K.V.K., N.B., D.G., M.H.P., Data Collection or Processing: P.C., K.V.K., N.B., D.G., M.H.P., Analysis or Interpretation: P.C., K.V.K., N.B., D.G., M.H.P., Literature Search: P.C., K.V.K., N.B., D.G., M.H.P., Writing: P.C., K.V.K., N.B., D.G., M.H.P.

Conflict of Interest: The authors declare no conflict of interest.

Financial Disclosure: The authors did not receive any financial support or grants for this study.

\section{References}

1. Flaatten $\mathrm{H}$, Oeyen $\mathrm{S}$, deLange DW. Predicting outcomes in very old ICU patients: time to focus on the past? Intensive Care Med 2018;44:13441345.

2. Guidet B, de Lange DW, Boumendil A, Leaver $S$, Watson $X$, Boulanger $C$, Szczeklik W, Artigas A, Morandi A, Andersen F, Zafeiridis T, Jung C, Moreno R, 
Walther S, Oeyen S, Schefold JC, Cecconi M, Marsh B, Joannidis M, Nalapko

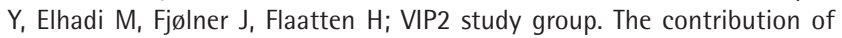
frailty, cognition, activity of daily life and comorbidities on outcome in acutely admitted patients over 80 years in European ICUs: the VIP2 study. Intensive Care Med 2020;46:57-69.

3. Flaatten $H$, De Lange DW, Morandi A, Andersen FH, Artigas A, Bertolini G, Boumendil A, Cecconi M, Christensen S, Faraldi L, Fjølner J, Jung S, Marsh B, Moreno R, Oeyen S, Öhman CA, Pinto BB, Soliman IW, Szczeklik W, Valentin A, Watson X, Zaferidis T, Guidet B; VIP1 study group. The impact of frailty on ICU and 30-day mortality and the level of care in very elderly patients ( $\geq$ 80 years). Intensive Care Med 2017;43:1820-1828.

4. Chen $X$, Mao G, Leng SX. Frailty syndrome: an overview. Clin Interv Aging 2014;9:433-441.

5. Fried $L P$, Tangen $C M$, Walston J, Newman $A B$, Hirsch $C$, Gottdiener J, Seeman T, Tracy R, Kop WJ, Burke G, McBurnie MA; Cardiovascular Health Study Collaborative Research Group. Frailty in older adults: evidence for a phenotype. J Gerontol A Biol Sci Med Sci 2001;56:M146-156.

6. Hao , Zhou L, Dong B, Yang M, Dong B, Weil Y. The role of frailty in predicting mortality and readmission in older adults in acute care wards: a prospective study. Sci Rep 2019;9:1207.

7. Evans DC, Cook CH, Christy JM, Murphy CV, Gerlach AT, Lindsey DE, Whitmill ML, Beery PR, Steinberg SM, Stawicki SPA. Comorbidity-polypharmacy scoring may improve outcome prediction in older trauma patients. Surgical Forum Abstracts 2010;211:59.

8. Amemiya $T$, Oda $K$, Ando $M$, Kawamura $T$, Kitagawa $Y$, Okawa $Y$, Yasui $A$, Ike $H$, Shimada $H$, Kuroiwa K, Nimura $Y$, Fukata $S$. Activities of daily living and quality of life of elderly patients after elective surgery for gastric and colorectal cancers. Ann Surg 2007;246:222-228.

9. Katz S, Downs TD, Cash HR, Grotz RC. Progress in development of the index of ADL. Gerontologist 1970;10:20-30.

10. Siriwardhana DD, Hardoon $S$, Rait G, Weerasinghe MC, Walters KR. Prevalence of frailty and prefrailty among community-dwelling older adults in low-income and middle-income countries: a systematic review and meta-analysis. BMJ Open 2018;8:e018195.

11. Pugh RJ, Ellison A, Pye K, Subbe CP, Thorpe CM, Lone NI, Clegg A. Feasibility and reliability of frailty assessment in the critically ill: a systematic review. Crit Care 2018;22:49.

12. Stawicki SP, Kalra S, Jones C, Justiniano CF, Papadimos TJ, Galwankar SC, Pappada SM, Feeney JJ, Evans DC. Comorbidity polypharmacy score and its clinical utility: A pragmatic practitioner's perspective. J Emerg Trauma Shock 2015;8:224-231.

13. United Nations. World Population Ageing 2019. 2019. 64. Available from: http://www.un.org/esa/population/publications/worldageing 19502050/
pdf/65executivesummaryspanish.pdf\%0Ahttp://link.springer.com/ chapter/10.1007/978-94-007-5204-7_6.

14. Valentini A, Federici M, Cianfarani MA, Tarantino U, Bertoli A. Frailty and nutritional status in older people: the Mini Nutritional Assessment as a screening tool for the identification of frail subjects. Clin Interv Aging 2018;13:1237-1244.

15. Hewitt J, Carter B, Vilches-Moraga A, Quinn TJ, Braude P, Verduri A, Pearce L, Stechman M, Short R, Price A, Collins JT, Bruce E, Einarsson A, Rickard F, Mitchell E, Holloway M, Hesford J, Barlow-Pay F, Clini E, Myint PK, Moug SJ, McCarthy K; COPE Study Collaborators. The effect of frailty on survival in patients with COVID-19 (COPE): a multicentre, European, observational cohort study. Lancet Public Health 2020;5:e444-451.

16. Montgomery C, Bagshaw SM. Frailty in the age of VIPs (very old intensive care patients). Intensive Care Med 2017;43:1887-1888.

17. Shamliyan T, Talley KM, Ramakrishnan R, Kane RL. Association of frailty with survival: a systematic literature review. Ageing Res Rev 2013;12:719-736.

18. Mubang RN, Stoltzfus JC, Cohen MS, Hoey BA, Stehly CD, Evans DC, Jones C, Papadimos TJ, Grell J, Hoff WS, Thomas P, Cipolla J, Stawicki SP. Comorbidity-Polypharmacy Score as Predictor of Outcomes in Older Trauma Patients: A Retrospective Validation Study. World J Surg 2015;39:20682075.

19. Housley BC, Stawicki SP, Evans DC, Jones C. Comorbidity-polypharmacy score predicts readmission in older trauma patients. J Surg Res 2015;199:237243.

20. Gómez C, Vega-Quiroga S, Bermejo-Pareja $F$, Medrano MJ, Louis ED, Benito-León J. Polypharmacy in the elderly: a marker of increased risk of mortality in a population-based prospective study (NEDICES). Gerontology 2015;61:301-309.

21. Evans DC, Cook CH, Christy JM, Murphy CV, Gerlach AT, Eiferman D, Lindsey DE, Whitmill ML, Papadimos TJ, Beery PR, Steinberg SM, Stawicki SPA. Comorbidity-polypharmacy scoring facilitates outcome prediction in older trauma patients. J Am Geriatr Soc 2012;60:1465-1470.

22. Nakazawa A, Nakamura K, Kitamura K, Yoshizawa Y. Association between activities of daily living and mortality among institutionalized elderly adults in Japan. J Epidemiol 2012;22:501-507.

23. Mossakowska M, Broczek $K$, Wieczorowska-Tobis $K$, Klich-Rączka A, Jonas M, Pawlik-Pachucka E, Safranow K, Kuznicki J, Puzianowska-Kuznicka $M$. Cognitive performance and functional status are the major factors predicting survival of centenarians in Poland. J Gerontol A Biol Sci Med Sci 2014;69:1269-1275. 